\section{Regional anesthesia in parturients with low platelet counts}

\section{To the Editor:}

The lowest platelet counts at which one can safely administer neuraxial anesthesia for labour and delivery is controversial. Published studies are few and sample sizes small. ${ }^{1-3}$ We report our institutional experience with thrombocytopenic parturients, probably the largest group to date.

Medical records from 1997 to 2002 of parturients with platelet counts $<100,000 \cdot \mu \mathrm{L}^{-1}$ during the peripartum period were reviewed for methods of anesthesia/analgesia for delivery, peripartum, and hospital course and incidence of neurological complications; 177 patients were identified. Of these, $170(96 \%)$ received regional anesthesia. Ninety percent of identified patients had platelet counts > $70,000 \cdot \mathrm{LL}^{-1}$; all received regional anesthesia for either vaginal or Cesarean delivery, as did all parturients with platelet counts $70,000 \cdot \mu \mathrm{L}^{-1}$ to $60,000 \cdot \mu \mathrm{L}^{-1}$ requesting regional anesthesia. In paturients with platelet counts between 50,000 to $60,000 \cdot \mu \mathrm{L}^{-1}$, six received regional anesthesia and one was denied. Spinal, instead of epidural, was more often chosen in this group than in those with counts $>60,000 \cdot \mu \mathrm{L}^{-1}(4 / 6$ vs $29 / 160 \mathrm{P}<0.005$, Chi square test), probably because five of seven parturients in this group presented for Cesarean delivery for worsening pre-eclampsia without being in labour and because of a perception among anesthesiologists of the lower risk of epidural hematoma associated with spinal $(1: 220,000) v s$ epidural anesthesia $(1: 150,000) .{ }^{4}$ Parturients with counts $<50,000 \cdot \mu \mathrm{L}^{-1}$ received regional anesthesia only after platelet transfusion.

In $82 \%$, the platelet count was over $60,000 \cdot \mu \mathrm{L}^{-1}$ at catheter removal in our study. In some women, platelet count decreased after epidural placement and the catheter was left in place for up to $36 \mathrm{hr}$ until the platelet count showed a steady rise. Five patients had counts < $50,000 \cdot \mu \mathrm{L}^{-1}$ (two of them, 36 and $38,000 \cdot \mu \mathrm{L}^{-1}$, respectively) when catheters were removed.

The causes of thrombocytopenia were gestational thrombocytopenia, pre-eclampsia, and idiopathic thrombocytopenia. There were no other associated coagulation abnormalities. No neurological complications were documented in any patients reviewed.

Our retrospective study by no means proves that it is safe to administer regional anesthesia to parturients with platelet counts $<100,000 \cdot \mu \mathrm{L}^{-1}$. Using the standard formulae for zero numerators, ${ }^{5}$ we estimate, with 95\% confidence, that the incidence of epidural hematoma in our population is not greater than $1.8 \%$. If our data are combined with other published reports, the expected incidence becomes even lower. Assessment of the incidence of a rare event is difficult in clinical practice. Therefore, in the absence of large, unfeasible studies, it is prudent to evaluate the risk-benefit ratio on a case-by-case basis before administering regional anesthesia to parturients.

Vladmir Frenk MD

William Camann MD

Kodali Bhavani Shankar MD

Boston, Massachusetts

\section{References}

1 Rolbin SH, Abbott D, Musclow E, Papsin F, Lie LM, Freedman J. Epidural anesthesia in pregnant patients with low platelet counts. Obstet Gynecol 1988; 71: 918-20.

2 Beilin $\Upsilon$, Zabn J, Comerford M. Safe epidural analgesia in thirty parturients with platelet counts between 69,000 and 98,000 $\mathrm{mm}^{-3}$. Anesth Analg 1997; 85: 385-8.

3 Rasmus KT, Rottman RL, Kotelko DM, Wright WC, Stone JJ, Rosenblatt RM. Unrecognized thrombocytopenia and regional anesthesia in parturients: a retrospective review. Obstet Gynecol 1989; 73: 943-6.

4 Vandermeulen EP, Van Aken H, Vermylen J. Anticoagulants and spinal-epidural anesthesia. Anesth Analg 1994; 79: 1165-77.

5 Hanley JA, Lippman-Hand A. If nothing goes wrong, is everything all right? Interpreting zero numerators. JAMA 1983 ; 249: 1743-5.

\section{Cricoid pressure application to awake volunteers: discomfort cannot be used to indicate appropriate force}

To the Editor:

Cricoid pressure is applied to unstarved patients undergoing anesthesia. Inadequate force risks aspiration, but adequate force within the currently recommended maxima can cause airway obstruction and cricoid collapse, even when correctly applied. ${ }^{1,2}$ We investigated whether discomfort in conscious subjects could predict airway compression measured indirectly by a decrease in peak expiratory flow rate (PEFR).

After local Research Ethics Committee approval, we recorded baseline measurements of height, weight, and PEFR in 30 consenting, blinded, ASA I-II volunteers. We applied increasing cricoid force in $5 \mathrm{~N}$ increments, and measured PEFR again if discomfort occurred, or a force of $40 \mathrm{~N}$ was reached. Cricoid force was measured 